This document is the accepted manuscript version of the following article:

Marel1i, E., Marino, C., Bolli, C., \& Villevieille, C. (2020). How to overcome Na deficiency in ful1 cel1 using P2-phase sodium cathode - a proof of concept study of $\mathrm{Na}$-rhodizonate used as sodium reservoir. Journal of Power Sources, 450, 227617 (8 pp.). https://doi.org/10.1016/j.jpowsour. 2019.227617

This manuscript version is made available under the CC-BY-NC-ND 4.0 1icense http://creativecommons.org/1icenses/by-nc-nd/4.0/

\title{
How to overcome Na deficiency in full cell using P2-phase sodium cathode - a proof of concept study of Na-rhodizonate used as sodium reservoir
}

\author{
Elena Marelli ${ }^{1}$, Cyril Marino $^{1^{*}}$, Christoph Bolli $^{1}$, Claire Villevieille $^{2^{*}}$ \\ ${ }^{1}$ Paul Scherrer Institut, Electrochemistry Laboratory, CH-5232 Villigen PSI, Switzerland \\ ${ }^{2}$ University Grenoble-Alpes, Grenoble INP, LEPMI laboratory, 38402 Saint Martin d'Hères,
} France

Email: claire.villevieille@gmail.com, cyrilmarino@hotmail.fr

\begin{abstract}
An organic, cheap and environmental friendly salt, namely disodium rhodizonate $\mathrm{Na}_{2} \mathrm{C}_{6} \mathrm{O}_{6}$, is tested as Na sacrificial template in a full-cell sodium-ion battery employing a sodium deficient P2 phase, $\mathrm{Na}_{0.67} \mathrm{Mn}_{0.6} \mathrm{Fe}_{0.25} \mathrm{Co}_{0.15} \mathrm{O}_{2}$ (NaMFC) as cathode, and a carbonaceous material as counter electrode. As a proof of concept, we demonstrated that the decomposition of the sacrificial organic material leads to enhance the specific capacity in the full-cell system, but the electrochemical results are mitigated by the high irreversibility caused by the side products coming from the sacrificial template decomposition. The mechanism of decomposition of the organic additive as well as its impact on the reaction mechanisms are investigated by online electrochemical mass spectroscopy (OEMS), microscopy and Raman/Infrared vibrational spectroscopy. Additionally, operando X-ray diffraction (XRD) demonstrates that during the oxidation of the disodium rhodizonate, the P2-phase undergoes a re-sodiation, which explains the benefit of $\mathrm{Na}_{2} \mathrm{C}_{6} \mathrm{O}_{6}$ as $\mathrm{Na}$ reservoir.
\end{abstract}

\section{Introduction}

Among several families of compounds tested as cathode materials for sodium-ion batteries (SiBs), layered oxides are the one delivering higher specific capacities (e.g. $219 \mathrm{mAhg}^{-1}$ for $\mathrm{NaMn}_{3} \mathrm{O}_{5}[1]$ with an average potential of $2.75 \mathrm{~V}$ vs. $\mathrm{Na}^{+} / \mathrm{Na}$ ).[2] Depending on how the oxide layers stack, and thus the geometry around the sodium ions, several phases are formed.[3]

P2 phases are better in terms of cycling stability and rate performance than the corresponding O3 phases, undergoing fewer phase transitions [4, 5] and providing higher specific charge.[6] However, the $\mathrm{Na}$ deficiency of the $\mathrm{P} 2$ phases, in which only $2 / 3$ of $\mathrm{Na}$ are present per formula unit in the pristine, limits the theoretical specific capacity in full-cell applications, where the 
anode material does not provide the infinite source of $\mathrm{Na}$ as in the half-cell (through $\mathrm{Na}$ metal). For example, the P2-phase $\mathrm{Na}_{0.67} \mathrm{Mn}_{0.5} \mathrm{Fe}_{0.5} \mathrm{O}_{2}$ developed by Yabuuchi et al. [7] delivers a specific capacity higher than $160 \mathrm{mAh} / \mathrm{g}$ when it is cycled vs. a Na metal counter electrode. However, Dugas et al. [8] have demonstrated that, without Na reservoir, this material provided only $125 \mathrm{mAh} / \mathrm{g}$ in full-cell. For $\mathrm{Na}_{0.44} \mathrm{MnO}_{2}$, known for its stability in aqueous environment,[9] a specific capacity of ca. $70 \mathrm{mAh} / \mathrm{g}$ is shown in the half-cell configuration, whereas only $30 \mathrm{mAh} / \mathrm{g}$ is reported for its cycling vs. a hard carbon counter electrode.[10]

In the literature, strategies were implemented to prevent the loss of specific capacity caused by $\mathrm{Na}$ deficiency consumed generally by surface reactions in full-cell systems.[10,11] On one hand, Hasa et al. [12] pre-cycled in half-cell a $\mathrm{Sb} / \mathrm{C}$ negative electrode in order to i) limit the loss of $\mathrm{Na}$ ions caused by the solid electrolyte interphase (SEI) formation and, ii) form a poorly sodiated $\mathrm{Na}_{\mathrm{x}} \mathrm{Sb}$ alloy to provide enough $\mathrm{Na}$ for the cathode during the discharge of the full-cell $\mathrm{Na}_{0.6} \mathrm{Ni}_{0.22} \mathrm{Fe}_{0.11} \mathrm{Mn}_{0.66} \mathrm{O}_{2} / / \mathrm{Sb} / \mathrm{C}$. During the $1^{\text {st }}$ charge, a specific capacity of $90 \mathrm{mAh} / \mathrm{g}$ was obtained at $15 \mathrm{~mA} / \mathrm{g}$ and, owing to the reported electrochemical improvement, a specific capacity of $120 \mathrm{mAh} / \mathrm{g}$ was reached during the discharge. On the other hand, the addition of a sacrificial $\mathrm{Na}$ reservoir to the cathode $[13,14]$, which needs to decompose in the operating voltage range of the battery, was assessed as a possible solution. Several compounds such as $\mathrm{Na}_{2} \mathrm{CO}_{3}$ and $\mathrm{Na}_{\mathrm{x}} \mathrm{P}$ were reported by the Tarascon's group and even lithium oxalate was explored in the Li-ion system [15]. Without sacrificial $\mathrm{Na}_{2} \mathrm{CO}_{3}$, the electrochemical performance in full-cell ( $\mathrm{P} 2-\mathrm{Na}_{\mathrm{x}} \mathrm{Ni}_{0.2} \mathrm{Mn}_{0.6} \mathrm{Co}_{0.2} \mathrm{O}_{2}$ vs. hard-carbon electrodes) does not exceed $70 \mathrm{mAh} / \mathrm{g}$ for a $\mathrm{Na}$ content of 0.7 atoms per formula unit, whereas $100 \mathrm{mAh} / \mathrm{g}$ was obtained in the presence of $\mathrm{Na}_{2} \mathrm{CO}_{3}$. Recently, Michel Armand and co-workers reported the usage of $\mathrm{Na}_{2} \mathrm{C}_{2} \mathrm{O}_{4}$ as sacrificial template to improve the electrochemical performance of $\mathrm{P} 2-$ $\mathrm{Na}_{0.67}\left[\mathrm{Fe}_{0.5} \mathrm{Mn}_{0.5}\right] \mathrm{O}_{2}$ [16] and $\mathrm{Na}_{3}(\mathrm{VO})_{2}\left(\mathrm{PO}_{4}\right)_{2} \mathrm{~F}$ [17]. In both cases, the sacrificial salt decomposed at high voltage generating extra $\mathrm{Na}$ ion, $\mathrm{CO}_{2}$ gases and lead to extra porosity in the composite electrode. The extra $\mathrm{Na}$ ions released in the system lead to an increase of the total specific capacity delivered by the full cell (hard carbon was used as negative electrode).

In the present case, we propose to use a commercial organic molecule as sacrificial compound, disodium rhodizonate $\mathrm{Na}_{2} \mathrm{C}_{6} \mathrm{O}_{6}$, known also in the literature as cathode material.[18-20] At this stage, we want to demonstrate that sacrificial templates are an easy alternative solution for the future commercialisation of Na-ion batteries. Indeed, P2 phases cathode are more stable than their $\mathrm{O} 3$ counterpart leading to a better cycling stability but P2 phases suffer from $\mathrm{Na}$ deficiency leading to poor energetic density. Thus, sacrificial template (or Na reservoir) can 
enhance the electrochemical performance on long-term cycling. Of course, disodium rhodizonate is only used here as a proof of concept material, and the results presented here should open a new research line dedicated to the development of sacrificial templates with suitable properties for electrochemistry, such as good electronic conductivity, high $\mathrm{Na}$ content and decomposition products that should have a positive impact on the electrolyte and electrodes (SEI). Thus, the $\mathrm{P} 2-\mathrm{Na}_{0.67} \mathrm{Mn}_{0.6} \mathrm{Fe}_{0.25} \mathrm{Co}_{0.15} \mathrm{O}_{2}$ phase (NaMFC), previously investigated in our group, was selected as cathode material in this study and cycled versus carbonaceous electrode material [21, 22]. For the cathode, we recently demonstrated [23] that only $0.43 \mathrm{Na}$ was extracted from the material during the $1^{\text {st }}$ charge ( $4.5 \mathrm{~V}$ upper cut off potential), resulting in a specific capacity of ca. $113 \mathrm{mAh} / \mathrm{g}$, whereas $0.52 \mathrm{Na}$ was re-intercalated during the discharge (to $2.1 \mathrm{~V}$ ) accounting for $140 \mathrm{mAh} / \mathrm{g}$ making this cathode an ideal candidate to study the impact of sacrificial template. Operando techniques (online electrochemical mass spectrometry (OEMS) and operando X-ray diffraction (XRD)) as well as post-mortem analysis (i.e. Raman/Infrared vibrational spectroscopies and scanning electron microscopy) were used to study the reaction mechanism of the cathode combined to the sacrificial template and understand how the Na reservoir operates.

\section{Results and discussion}

\section{Electrochemistry}

The electrochemical performance of $\mathrm{Na}_{2} \mathrm{C}_{6} \mathrm{O}_{6}$ as cathode material in half-cell configuration in different potential windows is shown in Figure 1. As reported in the literature [18-20], the material delivers stable specific capacity of ca. $200 \mathrm{mAh} / \mathrm{g}$ when cycled in reduction in halfcell in the $2.9-1.5 \mathrm{~V}$ vs. $\mathrm{Na}^{+} / \mathrm{Na}$. The extra specific charge observed during the first cycle (theoretical specific charge of $\mathrm{Na}_{2} \mathrm{C}_{6} \mathrm{O}_{6}=250 \mathrm{mAh} / \mathrm{g}$ ) might originate from the electrolyte decomposition, catalysed by the oxidation of rhodizonate, or further rhodizonate oxidation, as detailed later in the text. The same material cycled in oxidation between $2.1-4.5 \mathrm{~V} \mathrm{vs} . \mathrm{Na}^{+} / \mathrm{Na}$, shows a long potential plateau at ca. $3.75 \mathrm{~V}$ vs. $\mathrm{Na}^{+} / \mathrm{Na}$ before reaching the cut-off potential on the first charge. Again, the material is delivering a specific capacity of ca. $300 \mathrm{mAh} / \mathrm{g}$ during the desodiation, a bit higher than the theoretical capacity indicating that i) all $\mathrm{Na}$ ions get removed from the materials and, ii) the extra capacity might be linked to the electrolyte oxidation too. The following cycles show a complete absence of electrochemical activity, as 
shown in Figure 1b, a clear indication that the organic compound decomposes during the first oxidation at high voltage releasing lot of $\mathrm{Na}$ ions.
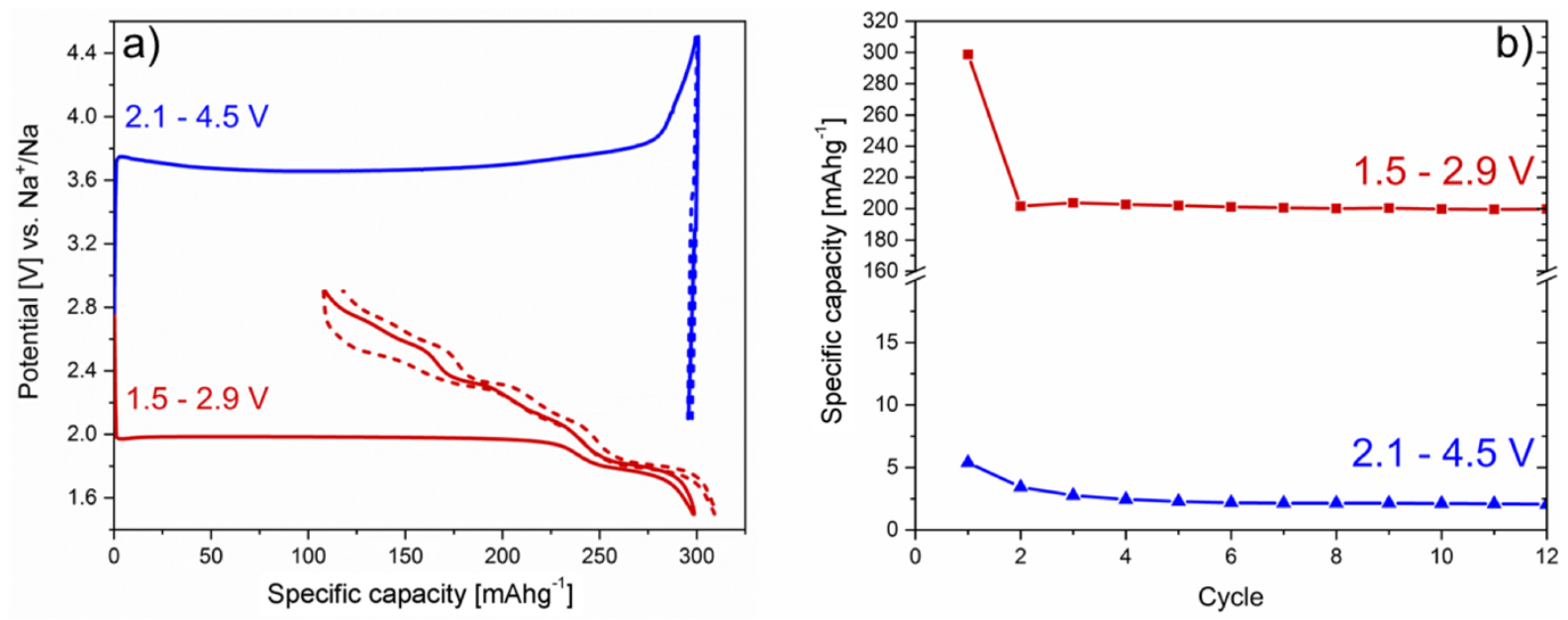

Figure 1: Galvanostatic curves plots (a) and electrochemical performance (b) of $\mathrm{Na}_{2} \mathrm{C}_{6} \mathrm{O}_{6}$ cycled in half-cell configuration in the electrochemical potential window reported in literature (red) [18] and in the electrochemical window used to cycle NaMFC (blue) [21]. In graph (a) the solid lines represent the first cycle and dotted lines the $2^{\text {nd }}$ cycle galvanostatic curves.

In order to assess the benefit of $\mathrm{Na}_{2} \mathrm{C}_{6} \mathrm{O}_{6}$ as $\mathrm{Na}$ reservoir, $\mathrm{NaMFC}$ electrodes mixed with different weight fractions of the organic compound (10\% and $20 \%)$ were cycled in full-cell configuration versus a carbonaceous material (Figure 2). The corresponding cathode desodiation (or charge) curve (Figure 2a) can be divided in three regions (Figure 2a). For the sake of clarity, the galvanostatic curves in half-cell of NaMFC and the carbonaceous material are depicted in Figure S1 (Supplementary Information). The region between $1.5 \mathrm{~V}$ and $2.5 \mathrm{~V}$ (i region in Figure 2a) is attributed to the SEI formation on the anode material [22] coupled with the oxidation of the Mn(III) in Mn(IV) of NaMFC [21]. As can be seen, this phenomenon is fully reversible regardless of the electrode composition. From $2.5 \mathrm{~V}$ to $4 \mathrm{~V}$ (for NaMFC and 90:10 electrodes) and to $3.8 \mathrm{~V}$ (for 80:20 electrode), a sloping region is present in the galvanostatic curves. This was assigned to the presence of a solid solution due to the progressive extraction of $\mathrm{Na}$ ions from $\mathrm{NaMFC}$, accompanied by the continuous oxidation of $\mathrm{Mn}$, and, at the counter electrode side, to the reaction of $\mathrm{Na}$ ions with the carbonaceous material. As can be seen, the processes are almost identical between the different electrode materials, but we can notice a change in the polarisation as a function of the percentage of rhodizonate. Indeed, the polarisation is lower for the electrode with the larger amount of additive, which is in agreement with the electronic conductivity of the rhodizonate (better than the one of the active materials) as seen in the electrochemical impedance spectroscopy spectra displayed in the Figure S2 of the Supporting Information. Following this slopping region, we can notice an almost linear last region above $4 \mathrm{~V}$ for NaMFC electrodes, which corresponds to 
a combination of i) the potential plateau of the carbonaceous counter electrode and, ii) the oxidation of the $\mathrm{Fe}(\mathrm{III})$. Interestingly, the galvanostatic curves of the $\mathrm{Na}_{2} \mathrm{C}_{6} \mathrm{O}_{6}$-containing electrodes (Figure 2a) show an additional feature, starting at $4 \mathrm{~V}$ for the 90:10 electrode and $3.8 \mathrm{~V}$ for the $80: 20$ electrode, indicating the oxidation of the rhodizonate template. We can notice an erratic behaviour of the cell during the decomposition, which might be attributed to a combination of events, among which but not limited to the formation of bubbles due to the observed gas release in the cell, and to the change in the electrode porosity that can lead to an uneven current distribution. During the discharge (sodiation), the galvanostatic curves present similar features with a continuous potential decrease and no additional contributions from the organic additive (see also the $2^{\text {nd }}$ cycle galvanostatic curves in Figure S3, Supporting Information). Additionally, the EIS measurement (Figure S4, Supporting Information), the NaMFC electrodes turned less resistive after one cycle which might be attributed to i) a favourable SEI, ii) a better wettability of the electrodes (after electrode breathing due to sodium reaction) and/or iii) to a change in the bulk conductivity that might have evolved with the $\mathrm{Na}$ content. In the case of the electrode containing the rhodizonate, we can instead notice that the resistances are almost identical to the pristine spectrum after one cycle, but the shape and the number of contributions is different. Indeed, the additional contribution might be coming from the decomposition/dissolution of the sacrificial salt leading to another surface layer chemistry (the frequency is different from the bare NaMFC sample), also the electrolyte resistance evolves due to the decomposition of the salt that might have polluted the electrolyte by soluble decomposition products.

The electrochemical performance of the full-cells with and without the disodium rhodizonate is shown in Figure $2 \mathrm{~b}$ and Figure S5 (Supporting Information). During the $1^{\text {st }}$ discharge 77, 82 and $90 \mathrm{mAh} / \mathrm{g}$ are obtained for NaMFC, NaMFC: $\mathrm{Na}_{2} \mathrm{C}_{6} \mathrm{O}_{6}$ 90:10 and NaMFC: $\mathrm{Na}_{2} \mathrm{C}_{6} \mathrm{O}_{6}$ 80:20, respectively indicating that indeed the decomposition of the rhodizonate can lead to an enhancement of the specific capacity. The coulombic efficiency, though, is drastically affected by the decomposition of the organic salt $(62 \%, 53 \%$ and $40 \%$ respectively for NaMFC, NaMFC: $\mathrm{Na}_{2} \mathrm{C}_{6} \mathrm{O}_{6}$ 90:10 and NaMFC: $\mathrm{Na}_{2} \mathrm{C}_{6} \mathrm{O}_{6}$ 80:20 electrodes). The positive impact of the sacrificial template lasts until the $7^{\text {th }}$ cycle, but a faster fading is observed from the $8^{\text {th }}$ cycle for the electrode containing the highest amount of the organic compound $\left(\mathrm{NaMFC}: \mathrm{Na}_{2} \mathrm{C}_{6} \mathrm{O}_{6}\right.$ 80:20). This suggests that the decomposition of the rhodizonate, or at least its relative concentration, might be detrimental for long-term cycling. The reason of the poor cell efficiency of this particular salt might be attributed to i) the decomposition products who are 
reacting with the organic electrolyte (yellow/reddish colour of the separator after the 1st cycle), and/or, ii) the pollution of the Na counter electrode, known to be unstable during cycling[2426], and/or, iii) the usage of PVDF binder which was already reported as detrimental in similar study case because of this enhanced decomposition leading to strong capacity fading. Regarding the binder, we could not do an experiment using Na-CMC as reported in the literature[20] because of the strong interaction between water-based solvent and our cathode material[27]. These observations indicate that even if the specific capacity of the composite electrodes increases in the presence of the salt, the decomposition products generated inside the cell are afterwards detrimental for a proper cycling mechanism. The decomposition/dissolution products could generate insulating organic molecules most probably sitting at the electrode/electrolyte interface or at the Na metal/electrolyte interface [24, 25], changing the cell resistance behavior. As we present here a proof of concept study, we think that all those pre-cited side effects could be overcome in the future by working directly on the development of tunable salt with improved electronic conductivity and decomposition products that could be favorable to the SEI. Thus, we focused also this study on the understanding of the interaction between the electroactive materials and sacrificial salt. We investigated the decomposition mechanism of the disodium rhodizonate, as well as its impact on the reaction of the P2-phase using several characterisation techniques.
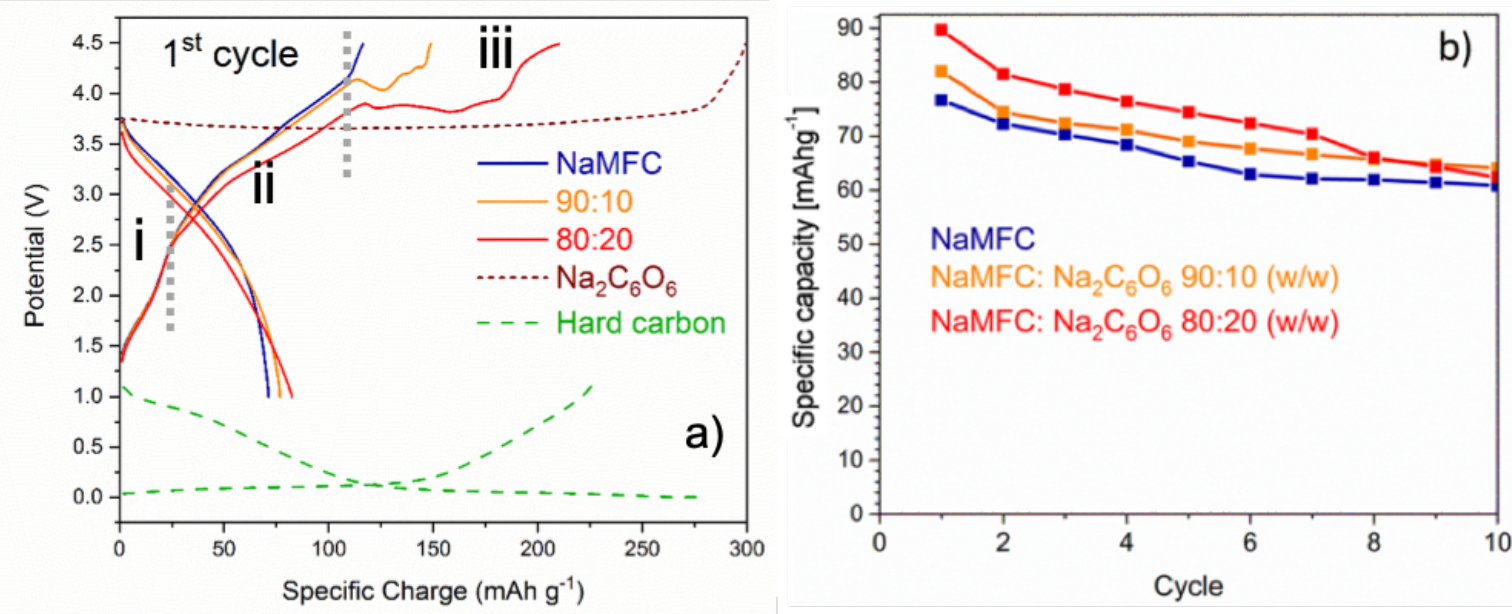

Figure 2: (a) Galvanostatic curves of the $1^{\text {st }}$ cycle of NaMFC, NaMFC: $\mathrm{Na}_{2} \mathrm{C}_{6} \mathrm{O}_{6} 90: 10$ (w/w), NaMFC: $\mathrm{Na}_{2} \mathrm{C}_{6} \mathrm{O}_{6}$ 80:20 (w/w) and $\mathrm{Na}_{2} \mathrm{C}_{6} \mathrm{O}_{6}$ cycled versus hard carbon (b) Electrochemical performance of the corresponding electrodes cycled at $\mathrm{C} / 10$ (the discharge specific capacity is plotted in Figure S5).

\section{Reaction mechanisms}

To better understand the role of the organic additive, its behaviour at high potential, without NaMFC, was first characterised by mean of several techniques. In the SEM cross-section image 
of the pristine electrode (Figure 3), randomly shaped dark particles of 2-8 $\mu \mathrm{m}$, assigned to the disodium rhodizonate, are embedded in a carbon/polymer matrix (lighter part). At the end of the $1^{\text {st }}$ charge, the cross-section SEM image shows large voids attributed to the disappearance of the $\mathrm{Na}_{2} \mathrm{C}_{6} \mathrm{O}_{6}$ particles, suggesting the dissolution of $\mathrm{Na}_{2} \mathrm{C}_{6} \mathrm{O}_{6}$ at high voltage, in agreement with the electrochemical results (displayed in Figure 2). Additionally, the charged state SEM image is more "charging" than the pristine one. This is in agreement with the polarisation increases present in the sodiation part of the galvanostatic plots and might indicate that the decomposition products of the disodium rhodizonate are less conductive and broadly distributed over the electrode sheet.

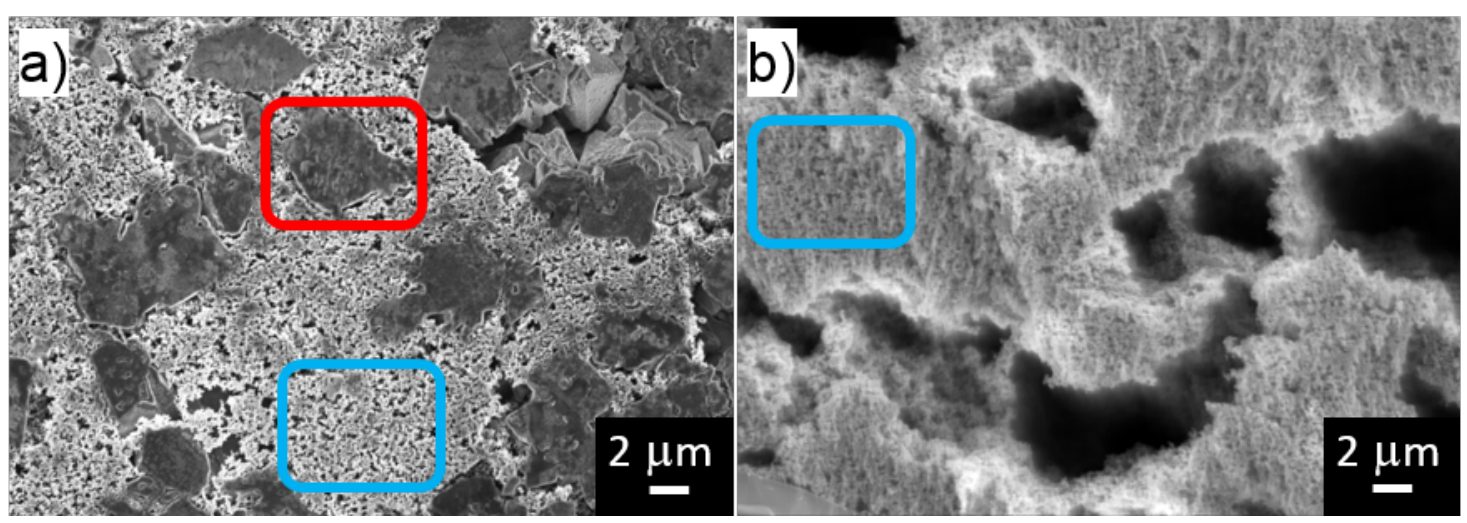

Figure 3: Cross-section SEM images of the pristine (a) and cycled (b) $\mathrm{Na}_{2} \mathrm{C}_{6} \mathrm{O}_{6}$ electrode. Examples of rhodizonate particles (red) and carbon matrix (blue) are circled for better clarity.

The decomposition of the organic additive after the first desodiation is also evidenced by infrared (IR) (Figure 4a) and Raman spectroscopies (Figure 4b). In the IR spectrum of the pristine $\mathrm{Na}_{2} \mathrm{C}_{6} \mathrm{O}_{6}$ electrode, the main bands at $480 \mathrm{~cm}^{-1}, 1050 \mathrm{~cm}^{-1}, 1200 \mathrm{~cm}^{-1}, 1490 \mathrm{~cm}^{-1}$, $1610 \mathrm{~cm}^{-1}$ and $1690 \mathrm{~cm}^{-1}$ are assigned to the $\mathrm{Na}_{2} \mathrm{C}_{6} \mathrm{O}_{6}$ compound (black ticks in Figure 4a) [28, 29]. After the first charge, the broad bands of the organic molecule vanish and new bands at higher wavelengths $\left(>1700 \mathrm{~cm}^{-1}\right)$ appear. According to the literature, those bands are attributed to the PVDF binder (orange ticks in Figure 4a) $[30,31]$ and to residual carbonate solvents (EC, DEC) coming from the electrolyte (blue ticks in Figure 4a) [32]. The Raman spectrum of the pristine electrode presents sharp and intense peaks at $350 \mathrm{~cm}^{-1}, 440 \mathrm{~cm}^{-1}, 560 \mathrm{~cm}^{-1}$ and $1520 \mathrm{~cm}^{-1}$, assigned to the disodium rhodizonate with a minor contribution of the PVDF binder $\left(805 \mathrm{~cm}^{-1}\right.$ and $\left.1440 \mathrm{~cm}^{-1}\right)$. Interestingly and in agreement with the SEM pictures, only the D and $\mathrm{G}$ bands (at $1320 \mathrm{~cm}^{-1}$ and $1590 \mathrm{~cm}^{-1}$ respectively) from the conductive carbon are detected in the charged electrode (see Figure 3). To summarise, both analyses show the disappearance of the $\mathrm{Na}_{2} \mathrm{C}_{6} \mathrm{O}_{6}$ related peaks from the charged electrode, without the formation of new peaks $[33,34]$. As reported in the literature, [18] the electrolyte turned orange/red upon high voltage 
due to the oxidation and further dissolution of the organic compound. This change in colour is attributed to the partial dissolution of the desodiated rhodizonate dianion $\left(\mathrm{C}_{6} \mathrm{O}_{6}{ }^{2-}\right)$.[19] Unfortunately, the UV-vis spectrum obtained by dissolving the pale red compound present on the separator after the $1^{\text {st }}$ charge in DMC, does not match with that of $\mathrm{C}_{6} \mathrm{O}_{6}{ }^{2-}$, nor with smaller cyclic oxocarbons [29, 35] (Figure 4c) indicating a more complex decomposition process behind, maybe linked also to the decomposition of the PVDF binder as reported in the literature[20].
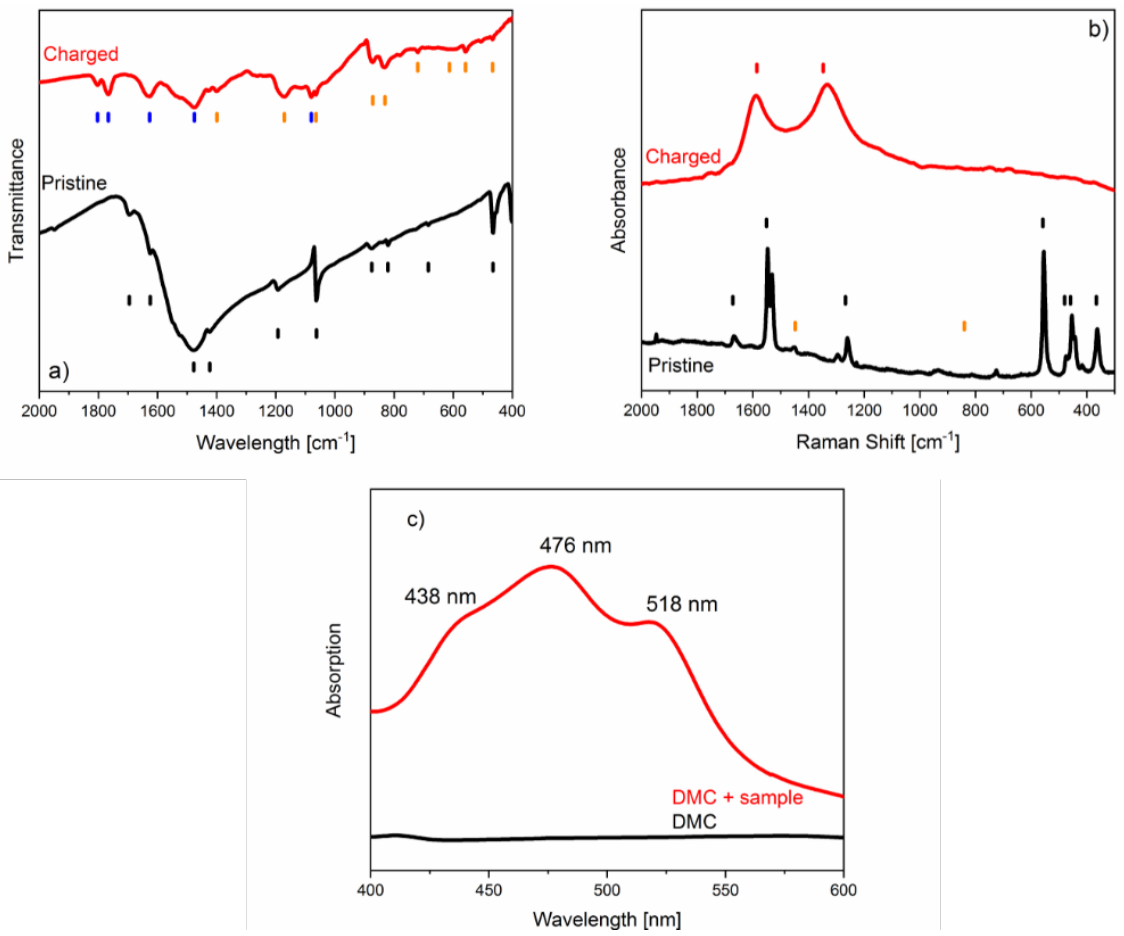

Figure 4: IR (a) and Raman (b) spectra of the pristine (black line) and charged (red line) $\mathrm{Na}_{2} \mathrm{C}_{6} \mathrm{O}_{6}$ electrode. $\mathrm{Na}_{2} \mathrm{C}_{6} \mathrm{O}_{6}$ (black ticks) [28, 29], carbon (red), PVDF (orange) [30, 31] and residual carbonates (blue)[32]. UV-vis spectra (c) of the electrolyte

+ charge separator $\left(\mathrm{Na}_{2} \mathrm{C}_{6} \mathrm{O}_{6}\right.$ half-cell battery charged to $4.5 \mathrm{~V}$ vs. $\left.\mathrm{Na}^{+} / \mathrm{Na}\right)$ in DMC (red line) and DMC (black line) as reference.

\section{Operando X-ray diffraction}

The NaMFC: $\mathrm{Na}_{2} \mathrm{C}_{6} \mathrm{O}_{6}$ 80:20 electrode evolution upon cycling was investigated by operando XRD (Figure 5). For completeness, operando XRD data on the disodium rhodizonate electrode are reported in Figure S6 (Supporting Information) and shows the disappearance of the pristine $\mathrm{Na}_{2} \mathrm{C}_{6} \mathrm{O}_{6}$ phase at the end of the potential plateau [36], in agreement with our previous observations made by vibrational spectroscopies. Upon charge of the NaMFC: $\mathrm{Na}_{2} \mathrm{C}_{6} \mathrm{O}_{6}$ 80:20 electrode, the peaks of $\mathrm{Na}_{2} \mathrm{C}_{6} \mathrm{O}_{6}$, represented by the (331) reflection at $26.3^{\circ}$, completely disappears at ca. $4.0 \mathrm{~V}$ vs. $\mathrm{Na}^{+} / \mathrm{Na}$ after the anomalous potential variation. When focussing on the NaMFC peaks at $15.4^{\circ}$ and $35.7^{\circ}$, the typical $\mathrm{P} 2 / \mathrm{O} 2$ reversible phase transition is observed: the formation of the (002) reflection at $17.3^{\circ}$, typical of the $\mathrm{O} 2$ structure, and the vanishing of 
the P2 related reflections, as previously described [23]. Concisely, upon charge the $a$ and $b$ lattice parameters (metal-oxide intra-layer) shrink, while the interlayer direction, $c$, undergoes only a minor elongation. The intensity of the $(00 l)$ peaks constantly decrease upon charge, leading to the formation of the $\mathrm{O} 2$ phase, at the end of charge, in which the remaining $\mathrm{Na}$ atoms are in octahedral coordination. Interestingly, when the disodium rhodizonate peaks start to disappear, all the NaMFC related peaks undergo a significant change: the lattice elongates back in the metal-oxide plane (see for instance the negative shift of the (100) peak) and the intensity of the P2 $(00 l)$ peaks begin again to increase. This behaviour is expected during a re-sodiation of the material, which could demonstrate the proof-of-concept of Na reservoir property of the disodium rhodizonate. After the potential fluctuation at around $4.1 \mathrm{~V}$ vs. $\mathrm{Na}^{+} / \mathrm{Na}$, the expected behaviour is restored with the positive shift of the (002) reflection for the $\mathrm{O} 2$ phase and the disappearance of the (002) reflection of the P2 structure. No further anomalies from the typical P2-NaMFC operando XRD pattern are observed upon further discharge and charge, as it can be seen in the Figure S7 (Supporting Information). Since the unexpected electrochemical behaviour during the dissolution of the $\mathrm{Na}_{2} \mathrm{C}_{6} \mathrm{O}_{6}$ could also be caused by an internal loss of contact, an additional experiment was performed in order to "simulate" the NaMFC relaxation at the same potential. In Figure S8 (Supporting Information), no alteration of the P2/O3 NaMFC phase equilibrium is observed (i.e. no peaks variations). This experiment allows to exclude the relaxation of the material as explanation of the evolution of the XRD patterns and potential observed in Figure 5. 


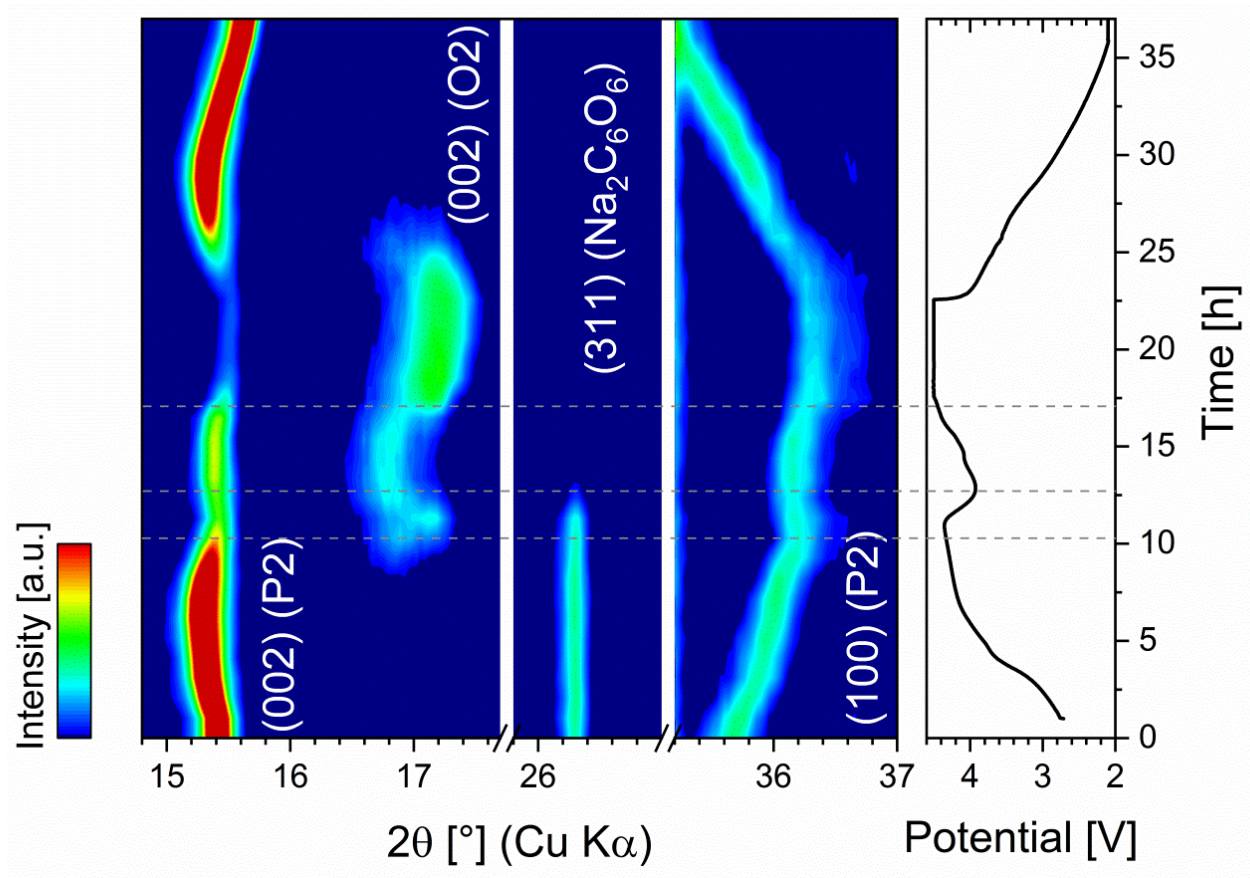

Figure 5: Selected region of the operando XRD patterns (contour plot) and galvanostatic curve obtained cycling the NaMFC: $\mathrm{Na}_{2} \mathrm{C}_{6} \mathrm{O}_{6}$ 80:20 composite electrode in half-cell configuration (vs. $\mathrm{Na}^{+} / \mathrm{Na}$ ). The $\mathrm{NaMFC}$ peaks are labelled specifying the phase changes ( $\mathrm{P} 2 \leftrightarrow \mathrm{O} 2)$ upon cycling.

\section{Online electrochemical mass spectrometry}

To study the evolution of the gaseous side-products during the electrochemical reactions, OEMS measurements were performed on the NaMFC and NaMFC: $\mathrm{Na}_{2} \mathrm{C}_{6} \mathrm{O}_{6}$ 80:20 electrodes in half-cell configuration (Figure 6). For NaMFC, the main evolution of the $\mathrm{CO}_{2}$ and $\mathrm{O}_{2}$ gasses occur at the beginning of the high-voltage potential plateau at potentials higher than $4.1 \mathrm{~V}$ vs. $\mathrm{Na}^{+} / \mathrm{Na}$ during charge. This behaviour is common for layered oxide materials and indicates an oxygen depletion from the surface of the NaMFC structure, which can become $\mathrm{CO}_{2}$ by reaction with the electrolyte [37-39]. In addition, at the end of charge, a $\mathrm{POF}_{3}$ release is observed and is attributed to the electrolyte decomposition [40, 41]. Interestingly, during the NaMFC: $\mathrm{Na}_{2} \mathrm{C}_{6} \mathrm{O}_{6} 80: 20$ charge, an additional peak of $\mathrm{CO}_{2}$ release is detected at potentials higher than $3.8 \mathrm{~V}$ vs. $\mathrm{Na}^{+} / \mathrm{Na}$ (see Figure 6 , right panel). This potential corresponds to the $\mathrm{Na}_{2} \mathrm{C}_{6} \mathrm{O}_{6}$ decomposition (see Figure 1), suggesting that the disodium rhodizonate is at least partially oxidized into $\mathrm{CO}_{2}$. 

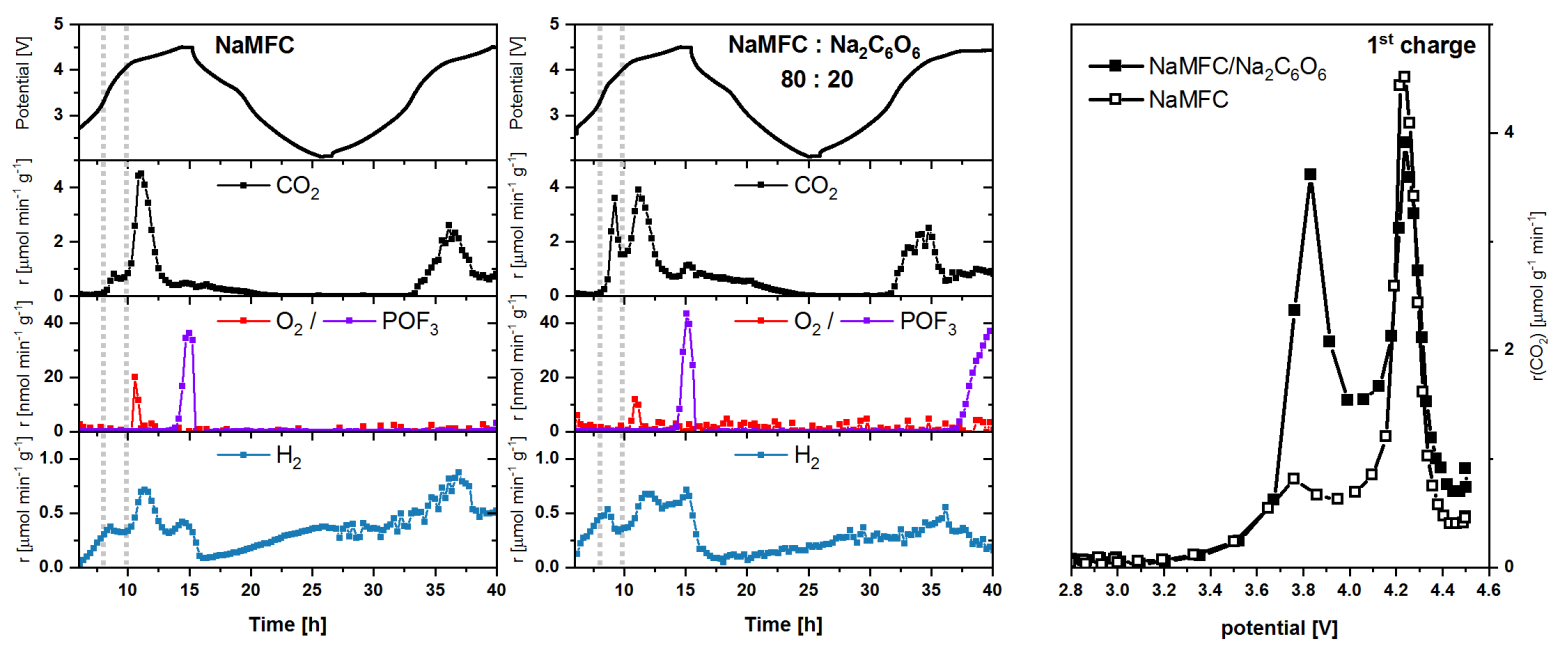

Figure 6: OEMS analysis on the NaMFC (left) and NaMFC: $\mathrm{Na}_{2} \mathrm{C}_{6} \mathrm{O}_{6}$ 80:20 (right) half-cell batteries showing the evolution of $\mathrm{CO}_{2}, \mathrm{O}_{2}, \mathrm{POF}_{3}$ and $\mathrm{H}_{2}$ during the cycles. The corresponding galvanostatic curves are shown at the top of the graphs. The right panel shows the $\mathrm{CO}_{2}$ evolution as a function of the potential for the $1^{\text {st }}$ charge.

Indeed, rhodizonate is known to undergo oxidation under thermal or photochemical conditions in neutral, slightly acidic or basic solutions, even though more rapidly in the latter according to the reaction [42]:

$\mathrm{Na}_{2} \mathrm{C}_{6} \mathrm{O}_{6}+2 \mathrm{OH}^{-} \rightarrow 2 \mathrm{Na}^{+}+\mathrm{C}_{5} \mathrm{O}_{5}^{2-}+\mathrm{CO}_{2}+\mathrm{H}_{2} \mathrm{O}+2 e^{-}$

The oxidation can eventually continue with the further decrease of the ring size:

$\mathrm{C}_{5} \mathrm{O}_{5}^{2-}+\mathrm{H}_{2} \mathrm{O} \rightarrow \mathrm{C}_{4} \mathrm{O}_{4}^{2-}+\mathrm{CO}_{2}+2 \mathrm{H}^{+}+e^{-}$

until the smaller cyclic oxocarbon $\mathrm{C}_{3} \mathrm{O}_{3}{ }^{2-}$ dianion is formed [43].

Since no fluctuation in the galvanostatic curve is present for the $\mathrm{Na}_{2} \mathrm{C}_{6} \mathrm{O}_{6}$ electrode, we can speculate that, for particles of $\mathrm{NaMFC}$ and $\mathrm{Na}_{2} \mathrm{C}_{6} \mathrm{O}_{6}$ in contact, a redox reaction occurs involving the reduction of $\mathrm{NaMFC}$ and oxidation of the rhodizonate molecule, possibly starting from the reactions (1) and (2).

Attempts to further characterise the reaction products and gain more insight on the reaction mechanism, using for instance NMR analysis, failed so far.

\section{Conclusion}

We validated here the proof-of-concept of the effective use of organic additives in composite cathode materials to enhance the electrochemical performance of $\mathrm{Na}$ full-cells using disodium rhodizonate, $\mathrm{Na}_{2} \mathrm{C}_{6} \mathrm{O}_{6}$. The specific capacity of the composite material increases during the first cycle even if the coulombic efficiency indicates a severe irreversible decomposition mechanism. This suggests that new salts need to be designed to improve the full-cell performance in the future. We determined also that this sacrificial template does not modify 
the reaction mechanisms of the cathode material, a very positive point, but it undergoes alone several complex reactions consisting on the oxidation and dissolution of the organic molecule in the electrolyte (releasing $\mathrm{CO}_{2}$ ) and the consequent re-insertion of the additional $\mathrm{Na}^{+}$in the layered oxide structure. The NaMFC deintercalation mechanism, consisting on the $\mathrm{P} 2 \rightarrow \mathrm{O} 2$ phase transition, is reversed by the insertion in the NaMFC structure of the additional $\mathrm{Na}^{+}$ions freed by the additive and restored once the $\mathrm{Na}^{+}$are deintercalated from the layered structure.

\section{Experimental part}

\section{Electrochemical tests}

The NaMFC polycrystalline compound was prepared according to ref [21]. The electrodes slurry consisted of an 80/10/10 (\% wt.) mixture of active material ( $\mathrm{NaMFC}+\mathrm{Na}_{2} \mathrm{C}_{6} \mathrm{O}_{6}(\mathrm{Sigma}$ Aldrich, 97\% purity) in different weight percentage)/carbon black (CB, SuperC65, Imerys)/polyvinylidene fluoride (PVDF, HSV-900, Arkema) dispersed in N-methyl-2pyrrolidone (NMP, Alfa Aesar). The slurry was cast on aluminium foil and dried in a vacuum oven at $80^{\circ} \mathrm{C}$ overnight. $13 \mathrm{~mm}$ electrodes were punched and further dried under dynamic vacuum at $120^{\circ} \mathrm{C}$ overnight prior to their transfer in an Ar-filled glovebox. Active material loadings are between $3.3 \mathrm{mg} / \mathrm{cm}^{2}$ to $5.5 \mathrm{mg} / \mathrm{cm}^{2}$.

Electrochemical cells were assembled in an Ar-filled glovebox using glass-fibres separator and either metallic sodium (Alfa Aesar, 99.8\% purity) (half-cells) [24] or carbonaceous material, prepared according to the procedure described elsewhere (with ca. $5.5 \mathrm{mg} / \mathrm{cm}^{2}$ average loading) [22] (full-cells), as counter electrode. The separator was soaked by and electrolyte made of $1 \mathrm{M}$ $\mathrm{NaPF}_{6}$ in a 1:1 mixture of ethylene carbonate (EC): diethyl carbonate (DEC) (Kishida Chemical, $0.45 \mathrm{ml}$ of electrolyte). The cells were cycled galvanostatically at $25^{\circ} \mathrm{C}$ with constant $\mathrm{C} / 10$ rate in the potential window $2.1-4.5 \mathrm{~V}$ vs. $\mathrm{Na}^{+} / \mathrm{Na}$ (half-cells) and between 0.05 and $4.49 \mathrm{~V}$ in full-cell (1.8 N/P balance, oversized negative). Measurements were monitored by an ASTROL cycling device.

\section{Electrochemical impedance spectroscopy (EIS)}

EIS measurement was performed with a three-electrodes cell setup (EL-cell) using a VMP3 potentiostat (BioLogic Science Instruments). The NaMFC and the 80:20 composite electrodes impedance spectra were measured at open circuit voltage and after the first cycle versus hard carbon. The impedance measurement was taken in a frequency range between $200 \mathrm{kHz}$ and $10 \mathrm{mHz}$. 


\section{X-ray diffraction (XRD)}

Self-standing electrodes were prepared by casting a mixture of 80/10/10 (\%wt.) active material/carbon black/PVDF Kynar Flex (Arkema) dispersed in acetone on a glass slide and dried in air. $11 \mathrm{~mm}$ in diameter electrodes were punched, dried under dynamic vacuum at $120^{\circ} \mathrm{C}$ overnight and stored in an Ar-filled glovebox. Active material loadings were around $7 \mathrm{mg} / \mathrm{cm}^{2}$ and the electrolyte volume introduced in the cell was $0.25 \mathrm{ml}$ of electrolyte. For this measurement, the cell was cycled in constant current, constant voltage protocol at $\mathrm{C} / 20$ rate. Operando XRD patterns were collected in Bragg-Brentano configuration at room temperature on a PANalytical Empyrean diffractometer using copper Ka radiation. The measurements were performed using an in-house made in situ XRD cell [44] and each pattern was acquired for $1 \mathrm{~h}$ in the $13-55^{\circ}$ angular range with a step size of $0.033^{\circ}$.

\section{Scanning Electron Microscope (SEM)}

The cross sections of pristine and cycled electrodes were obtained using an IM4000 ion-milling system (Hitachi). Continuous $\mathrm{Ar}^{+}$beam irradiation at $4.0 \mathrm{kV}$ (30 reciprocation $/ \mathrm{min}$ and a $30^{\circ}$ swing for $4 \mathrm{~h}$ ). SEM measurements were performed in a Carl Zeiss Ultra55 scanning electron microscope at $3 \mathrm{kV}$ using the secondary electron and InLens mode.

\section{Online electrochemical mass spectrometry (OEMS)}

OEMS electrodes were prepared by casting an 80:10:10 (\% wt.) mixture of active material/carbon black (CB, SuperC65, Imerys)/polyvinylidene fluoride (PVDF, HSV-900, Arkema) dispersed in N-methyl-2-pyrrolidone (NMP, Alfa aesar) onto Celgard 2400 foil. The electrode sheet was dried at $80^{\circ} \mathrm{C}$ in a vacuum oven overnight. $18 \mathrm{~mm}$ electrodes were punched, further dried at $80^{\circ} \mathrm{C}$ in a dynamic oven and directly inserted in an Ar filled glovebox. Active material loadings were around $1.2 \mathrm{mg} / \mathrm{cm}^{2}$ and the electrolyte volume introduced in the cell was $0.1 \mathrm{ml}$ of electrolyte. For this measurement, the cell was cycled using constant current, constant voltage protocol at $\mathrm{C} / 20$ rate.

The OEMS setup, already described elsewhere, [45, 46] operates with a quadrupole mass spectrometer (QMS 200, Pfeiffer) for partial pressure measurements, a pressure transducer (PAA-33X, Keller Druck AG) for total cell pressure, temperature, and internal volume determination, stainless steel gas pipes and Swagelok fittings ( $3 \mathrm{~mm}$ compression tube fittings, Swagelok, OH, US) to connect the OEMS cell, a set of solenoid valves (2-way magnetic valve, 
Series 99, silver-plated nickel seal, Parker) and a scroll pump (nXDS15i, EDWARDS GmbH) for efficient flushing. The magnetic valves are electronically controlled with a Solid State Relay Module (NI 9485 measurement System, National Instruments) connected to a computer with a LabView Software (NI Labview 2013, National Instruments). For partial pressure and gas evolution rate analysis $1.3 \mathrm{~mL}$ of gas are extracted regularly from the headspace $(\sim 4 \mathrm{~mL})$ of the cell and replaced by pure Ar (quality 5.0). Calibration gas bottles were utilized to relate the MS ion-current signals at $m / z=2,32$ and 44 to known concentrations of $\mathrm{H}_{2}, \mathrm{O}_{2}$ and $\mathrm{CO}_{2}$ (1000 ppm of $\mathrm{H}_{2}$, and $\mathrm{CO}_{2}$ in Ar, respectively), before and after the measurement. The calibration for $\mathrm{POF}_{3}(\mathrm{~m} / \mathrm{z}=85)$ was performed by releasing a defined amount of gas by a thermal reaction and was described elsewhere [47].

\section{Vibrational spectroscopy}

FT-IR spectra of the pristine and charged electrodes were collected in vacuum on a FTIR/ATR Spectrometer (Bruker Vertex 70v) in the $400-4000 \mathrm{~cm}^{-1}$ wavelength range. The cycled battery was disassembled in an Ar-filled glovebox, the cathode electrode extracted and washed with dimethylcarbonate (DMC). Part of the cycled and pristine electrodes were mixed with $\mathrm{KBr}$ (standard IR grade, Sigma Aldrich) and pressed into pellets.

Raman spectra on the same pristine and charged electrodes used for the IR measurements were collected on a Labram HR800 Raman microscope (HORIBA Jobin Yvon) equipped with a HeNe laser.

\section{UV-vis}

A $\mathrm{Na}_{2} \mathrm{C}_{6} \mathrm{O}_{6}$ electrode was charged to $4.5 \mathrm{~V}$ vs. $\mathrm{Na}^{+} / \mathrm{Na}$ in a half-cell and the potential was held for $7 \mathrm{~h}$. The cell was then disassembled in an Ar filled glovebox and the separator was carefully removed and soaked for $10 \mathrm{~min}$ in $2 \mathrm{ml}$ of DMC. The UV-vis spectra of the so prepared sample and DMC solution (as reference) were collected using sealed quartz cuvettes with an UV-Vis Varian Cary 500 spectrophotometer.

\section{Acknowledgment}

Dr. Eibar Flores is acknowledged for the Raman data acquisition. The SCCER network (Swiss Competence Centre for Heat and Electricity Storage) and the PSI Career return program are acknowledged for funding.

\section{Supporting Information}


Galvanostatic curves of the $1^{\text {st }}$ cycle in half-cell for the cathode and the anode material; Galvanostatic curves of the first cycle in full-cell with the impact of the Na-rhodizonate; Normalised galvanostatic cycles of the second cycle in full-cell with the impact of the Narhodizonate; Table summarizing the initial coulombic efficiency; Contour plot representation of the operando XRD measurement of the Na-rhodizonate alone and of the full cell with $20 \%$ of Na-rhodizonate.

\section{References}

1. Guo, S., et al., A High-Capacity, Low-Cost Layered Sodium Manganese Oxide Material as Cathode for Sodium-Ion Batteries. ChemSusChem, 2014. 7(8): p. 2115-2119.

2. Choi, J.W. and D. Aurbach, Promise and reality of post-lithium-ion batteries with high energy densities. Nature Reviews Materials, 2016. 1: p. 16013.

3. Delmas, C., J.-J. Braconnier, and P. Hagenmuller, A new variety of LiCoO2 with an unusual oxygen packing obtained by exchange reaction. Materials Research Bulletin, 1982. 17(1): p. 117-123.

4. Liu, L., et al., High-Performance P2-Type Na2/3(Mn1/2Fe1/4Co1/4)O2 Cathode Material with Superior Rate Capability for Na-Ion Batteries. Advanced Energy Materials, 2015. 5(22): p. 1500944.

5. $\quad \mathrm{Li}, \mathrm{X}$., et al., O3-type $\mathrm{Na}(\mathrm{MnO} 0.25 \mathrm{Fe} 0.25 \mathrm{Co0} .25 \mathrm{NiO} .25) \mathrm{O}$ : A quaternary layered cathode compound for rechargeable Na ion batteries. Electrochemistry Communications, 2014. 49: p. 51-54.

6. Yabuuchi, N., et al., Research Development on Sodium-Ion Batteries. Chemical reviews, 2014. 114(23): p. 11636-11682.

7. Yabuuchi, N., et al., P2-type Nax[Fe1/2Mn1/2]O2 made from earth-abundant elements for rechargeable Na batteries. Nature Materials, 2012. 11: p. 512.

8. Dugas, R., et al., Optimization of Na-Ion Battery Systems Based on Polyanionic or Layered Positive Electrodes and Carbon Anodes. Journal Electrochem. Soc., 2016. 163(6): p. A867-A874.

9. Dall'Asta, V., et al., Aqueous Processing of Na0.44MnO2 Cathode Material for the Development of Greener Na-Ion Batteries. ACS Appl Mater Interfaces, 2017. 9(40): p. 34891-34899.

10. Tsai, C.-L., et al., LiZLa3Zr2O12 Interface Modification for Li Dendrite Prevention. ACS Applied Materials \& Interfaces, 2016. 8(16): p. 10617-10626.

11. Yang, Q., et al., Advanced P2-Na2/3Ni1/3Mn7/12Fe1/12O2 Cathode Material with Suppressed P2-O2 Phase Transition toward High-Performance Sodium-Ion Battery. ACS Applied Materials \& Interfaces, 2018. 10(40): p. 34272-34282.

12. Hasa, I., S. Passerini, and J. Hassoun, A rechargeable sodium-ion battery using a nanostructured $\mathrm{Sb}-\mathrm{C}$ anode and P2-type layered Na0.6Ni0.22Fe0.11Mn0.66O2 cathode. RSC Advances, 2015. 5(60): p. 48928-48934.

13. Zhang, B., et al., Insertion compounds and composites made by ball milling for advanced sodium-ion batteries. Nature Communications, 2016. 7: p. 10308.

14. Sathiya, M., et al., Dual Stabilization and Sacrificial Effect of Na2CO3 for Increasing Capacities of Na-Ion Cells Based on P2-NaxMO2 Electrodes. Chemistry of Materials, 2017. 29(14): p. 5948-5956.

15. Solchenbach, S., et al., Lithium Oxalate as Capacity and Cycle-Life Enhancer in LNMO/Graphite and LNMO/SiG Full Cells. Journal of The Electrochemical Society, 2018. 165(3): p. A512-A524. 
16. Martínez De llarduya, J., et al., Towards high energy density, low cost and safe Na-ion full-cell using P2-NaO.67[FeO.5Mn0.5]O2 and Na2C4O4 sacrificial salt. Electrochimica Acta, 2019. 321: p. 134693.

17. Shanmukaraj, D., et al., Highly Efficient, Cost Effective, and Safe Sodiation Agent for HighPerformance Sodium-Ion Batteries. ChemSusChem, 2018. 11(18): p. 3286-3291.

18. Chihara, K., et al., Cathode properties of Na2C6O6 for sodium-ion batteries. Electrochimica Acta, 2013. 110: p. 240-246.

19. Lee, M., et al., High-performance sodium-organic battery by realizing four-sodium storage in disodium rhodizonate. Nature Energy, 2017. 2(11): p. 861-868.

20. Wang, C., et al., Manipulation of Disodium Rhodizonate: Factors for Fast-Charge and FastDischarge Sodium-Ion Batteries with Long-Term Cyclability. Advanced Functional Materials, 2016. 26(11): p. 1777-1786.

21. Marino, C., E. Marelli, and C. Villevieille, Impact of cobalt content in Na0.67MnxFeyCozO2 ( $x+$ $y+z=1$ ), a cathode material for sodium ion batteries. RSC Advances, 2017. 7(23): p. 13851-13857.

22. Marino, C., et al., Biowaste Lignin-Based Carbonaceous Materials as Anodes for Na-lon Batteries. Journal of The Electrochemical Society, 2018. 165(7): p. A1400-A1408.

23. Marelli, E., et al., Co-Free P2-Na0.67MnO.6Fe0.25AlO.15O2 as Promising Cathode Material for Sodium-Ion Batteries. ACS Applied Energy Materials, 2018. 1(11): p. 5960-5967.

24. Conder, J. and C. Villevieille, How reliable is the Na metal as a counter electrode in Na-ion half cells? Chemical Communications, 2019. 55(9): p. 1275-1278.

25. Pfeifer, K., et al., Can Metallic Sodium Electrodes Affect the Electrochemistry of Sodium-Ion Batteries? Reactivity Issues and Perspectives. ChemSusChem. 0(0).

26. Rupp, R. and A. Vlad, On the Reliability of Sodium Metal Anodes: The Influence of Neglected Parameters. Journal of The Electrochemical Society, 2019. 166(14): p. A3122-A3131.

27. Marino, C., et al., Impact of Water-Based Binder on the Electrochemical Performance of P2Na0.67MnO.6Fe0.25Co0.15O2 Electrodes in Na-Ion Batteries. Batteries-Basel, 2018. 4(4).

28. Bailey, R.T., Vibrational spectra and structure of the rhodizonate dianion. Journal of the Chemical Society B: Physical Organic, 1971(0): p. 627-629.

29. Takahashi, M., K. Kaya, and M. Ito, Resonance Raman scattering and the Jahn-Teller effect of oxocarbon ions. Chemical Physics, 1978. 35(3): p. 293-306.

30. Demeaux, J., et al., LiNiO.4Mn1.604/Electrolyte and Carbon Black/Electrolyte High Voltage Interfaces: To Evidence the Chemical and Electronic Contributions of the Solvent on the CathodeElectrolyte Interface Formation. Journal of The Electrochemical Society, 2012. 159(11): p. A1880A1890.

31. Boccaccio, T., et al., Characterization of PVDF membranes by vibrational spectroscopy. Journal of Membrane Science, 2002. 210(2): p. 315-329.

32. Chen, C.H. and K. Amine, lonic conductivity, lithium insertion and extraction of lanthanum lithium titanate. Solid State Ionics, 2001. 144(1): p. 51-57.

33. Kolev, T., B. Koleva, and M. Spiteller, Solid-state linear polarized IR-spectroscopy of croconic and rhodizonic acids, in Open Chemistry. 2008. p. 393.

34. Souza, N.L.G.D., et al., J. Braz. Chem. Soc., 2015. 26(6): p. 1247-1256.

35. Chalmers, R.A. and G.M. Telling, A reassessment of rhodizonic acid as a qualitative reagent. Microchimica Acta, 1967. 55(6): p. 1126-1135. 
36. Dinnebier, R.E., H. Nuss, and M. Jansen, Disodium rhodizonate: a powder diffraction study. Acta Crystallographica Section E, 2005. 61(10): p. m2148-m2150.

37. Luo, K., et al., Anion Redox Chemistry in the Cobalt Free 3d Transition Metal Oxide Intercalation Electrode Li[LiO.2NiO.2MnO.6]O2. Journal of the American Chemical Society, 2016. 138(35): p. 1121111218.

38. Castel, E., et al., Differential Electrochemical Mass Spectrometry Study of the Interface of $x$ Li2MnO3.(1-x)LiMO2 ( $M=\mathrm{Ni}, \mathrm{Co}$, and Mn) Material as a Positive Electrode in Li-lon Batteries. Chemistry of Materials, 2014. 26(17): p. 5051-5057.

39. Jung, R., et al., Oxygen Release and Its Effect on the Cycling Stability of LiNixMnyCozO2 (NMC) Cathode Materials for Li-Ion Batteries. Journal of The Electrochemical Society, 2017. 164(7): p. A1361A1377.

40. Guéguen, A., et al., Decomposition of LiPF6 in High Energy Lithium-Ion Batteries Studied with Online Electrochemical Mass Spectrometry. Journal of The Electrochemical Society, 2016. 163(6): p. A1095-A1100.

41. Metzger, M., et al., Origin of H2 Evolution in LIBs: H2O Reduction vs. Electrolyte Oxidation. Journal of The Electrochemical Society, 2016. 163(5): p. A798-A809.

42. Zhao, B. and M.H. Back, The photochemistry of the rhodizonate dianion in aqueous solution. Canadian Journal of Chemistry, 1991. 69(3): p. 528-532.

43. West, R., Chemistry of the Oxocarbons. Israel Journal of Chemistry, 1980. 20(3-4): p. 300-307.

44. Bleith, P., et al., In situ X-ray diffraction characterisation of Fe0.5TiOPO4 and Cu0.5TiOPO4 as electrode material for sodium-ion batteries. Electrochimica Acta, 2015. 176: p. 18-21.

45. He, M., et al., J. Electrochem. Soc. , 2016. 163 (2): p. A83-A89.

46. He, M., Elucidating interface reactions in Li-ion batteries and supercapacitors by in situ gas analysis. 2017, ETH Zürich.

47. Bolli, C., et al., Operando Monitoring of F- Formation in Lithium Ion Batteries. Chemistry of Materials, 2019. 31(4): p. 1258-1267. 
TOC.
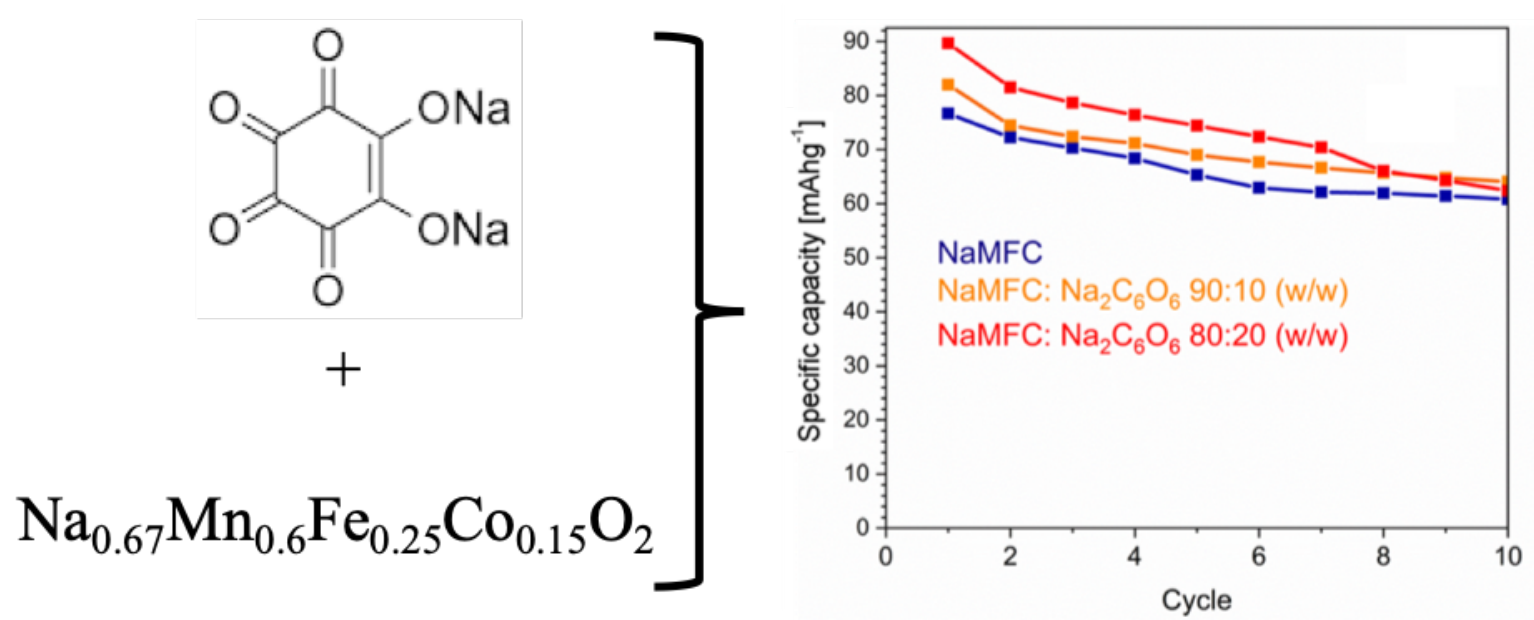